\title{
WEBINAR DAN PENDAMPINGAN DARING PENULISAN ARTIKEL HASIL PENELITIAN PADA JURNAL NASIONAL TERAKREDITASI BAGI GURU BAHASA INDONESIA TINGKAT SMA KOTA BENGKULU
}

\author{
Dian Eka Chandra Wardhana ${ }^{1 *}$, Rokhmat Basuki ${ }^{2}$, Noermanzah ${ }^{3}$ \\ Program Studi Magister Pendidikan Bahasa Indonesia, Universitas Bengkulu, Indonesia \\ * Penulis Korespodensi : dec.wardhana@unib.ac.id
}

\begin{abstract}
Abstrak
Pemahaman guru bahasa Indonesia tingkat SMA di Kota Bengkulu terhadap penulisan artikel ilmiah hasil penelitian masih rendah. Hal ini dibuktikan dengan masih sedikit jumlah publikasi guru bahasa Indonesia di jurnal nasional terakreditasi dan berdampak pada guru sulit untuk naik pangkat. Untuk itu, tujuan pengabdian kepada masyarakat ini untuk memberikan pemahaman kepada guru bahasa Indonesia SMA di Kota Bengkulu dalam menulis artikel ilmiah dan cara mempublikasikannya di jurnal nasional terakreditasi melalui kegiatan webinar dan pendampingan. Metode pengabdian kepada masyarakat menggunakan metode webinar dan pendampingan secara daring melalui Zoom Cloud Meeting. Peserta berjumlah 37 guru bahasa Indonesia SMA Kota Bengkulu. Teknik pengabdian kepada masyarakat menggunakan teknik ceramah, diskusi, dan praktik. Teknik pengumpulan data menggunakan teknik angket, dokumentasi, dan observasi. Hasil webinar menunjukkan bahwa guru bahasa Indonesia sudah maтрu menulis artikel dengan cukup baik, mulai dari menulis judul, abstrak, pendahuluan, metode, hasil penelitian, pembahasan, simpulan dan saran, serta daftar pustaka. Akan tetapi, beberapa guru masih kesulitan dalam menuangan bagian pendahuluan terutama memetakan posisi penelitian berdasarkan hasil penelitian relevan, kesulitan menuangkan pembahasan terutama menemukan kebaruan hasil penelitiannya, dan kesulitan mencari referensi dari jurnal online. Kemudian, dari hasil pendampingan, guru bahasa Indonesia masih kesulitan dalam submit dan proses memperbaiki artikel di sistem OJS.
\end{abstract}

Kata kunci: webinar, pendampingan, artikel jurnal ilmiah, jurnal nasional terakreditasi

\begin{abstract}
The understanding of Indonesian high school level teachers in Bengkulu City on writing scientific articles on research results is still low. This is evidenced by the small number of Indonesian language teacher publications in accredited national journals and it has an impact on teachers having difficulty advancing in rank. For this reason, the aim of this community service is to provide understanding to Indonesian high school teachers in Bengkulu City in writing scientific articles and how to publish them in accredited national journals through webinars and mentoring activities. The community service method uses webinars and online mentoring through the Zoom Cloud Meeting. Participants totaled 37 Indonesian high school teachers in Bengkulu City. Community service techniques use lecture, discussion, and practice techniques. Data collection techniques using questionnaires, documentation, and observation. The results of the webinar indicate that the Indonesian language teacher is able to write articles quite well, starting from writing titles, abstracts, introductions, methods, research results, discussions, conclusions and suggestions, and bibliography. However, some teachers still have difficulty in pouring out the introductory section, especially mapping research positions based on relevant research results, difficulty in pouring out the discussion, especially finding the novelty of their research results, and difficulty finding references from online journals. Then, from the results of mentoring, Indonesian language teachers still have difficulty in submitting and the process of fixing articles in the OJS system.
\end{abstract}

Keywords: webinars; accompaniment; scientific journal articles; accredited national journal 


\section{Pendahuluan}

Profesionalitas guru bahasa Indonesia sudah diatur dalam Undang-Undang RI Nomor 14 tahun 2005, pasal 1 ayat 1, "Guru adalah pendidik profesional dengan tugas utama mendidik, mengajar, membimbing, mengarahkan, melatih, menilai dan mengevaluasi peserta didik pada pendidikan anak usia dini jalur pendidikan formal, pendidikan dasar, dan pendidikan menengah." Kemudian, pada pasal 1 ayat 2 disebutkan "Profesional adalah pekerjaan atau kegiatan yang dilakukan oleh seseorang dan menjadi sumber penghasilan kehidupan yang memerlukan keahlian, kemahiran atau kecakapan yang memenuhi standar mutu atau norma tertentu serta memerlukan pendidikan profesi." Sejalan dengan undang-undang tersebut, keprofesionalan diatur pula melalui PP No. 19 tahun 2005 pasal 28 tentang profesionalitas guru yang setidaknya harus memenuhi persyaratan kompetensi, meliputi: kompetensi pedagogik, kompetensi kepribadian, kompetensi profesional, dan kompetensi sosial.

Khususnya kompetensi profesional guru bahasa Indonesia harus menguasai bidang keilmuan di bidang bahasa Indonesia. Salah satu cara untuk meningkatkan kemampuan keilmuan di bidang bahasa Indonesia yaitu dengan cara menulis karya tulis (Firmansyah dan Syafrina, 2018: 11). Menurut Yanti dkk., (2018:83) faktor utama masih rendahnya publikasi karya ilmiah guru yang tergabung dalam MGMP Bahasa Indonesia SMA/SMK Kota Bengkulu adalah pemahaman tentang teknik penulisan yaitu sebesar 30\% atau sebanyak 11 orang dari peserta pelatihan. Faktor lainnya yang menyebabkan rendahnya tingkat publikasi karya ilmiah peserta pelatihan yaitu kurangnya pemahaman struktur, referensi dan media publikasi karya ilmiah yang telah mereka hasilkan. Selain faktor kemampuan, faktor lain yang menyebabkan rendahnya tingkat publikasi karya ilmiah peserta pelatihan adalah faktor psikologis dan faktor ekonomi.

Kekurangan penulisan artikel ilmiah juga biasanya terletak pada penulisan tata bahasa dan teknik menulis yang masih bersifat prosedural (Blumner, 2008: 21). Ada kecenderungan bagi penulis pemula sering melakukan kesalahan dalam hal kemenarikan isi, kesesuaian ini, penulisan ejaan, tanda baca, diksi, kelengkapan, keruntutan, kalimat sudah efektif, dan paragraf sudah padu serta tulisan yang tidak konsisten dalam menyajikan isi tulisan (Musaffak dan Pangesti, 2018: 198). Hal itu disebabkan belum ada singkronisasi tulisan dengan pedoman penulisan yang berlaku dalam hal ini jurnal nasional akreditasi yang dituju. Menulis artikel ilmiah sebaiknya juga harus mengandung kebaruan sehingga dibutuhkan kemampuan bahan bacaan dari referensi baik dari jurnal atau buku. Dengan memiliki referensi yang memadai penulis dapat menuangkan gagasannya tentang hal yang menarik dan adanya kebaruan dari hasil penelitian di dalam bagian pembahasan atau isi artikel (Kellog, 2008:2).

Artikel ilmiah adalah tulisan yang berisi laporan yang sistematis mengenai hasil penelitian atau hasil kajian yang disajikan kepada masyarakat ilmiah tertentu (mahasiswa, dosen, guru, peneliti, ilmuan, dan lainnya) untuk dikaji dan didiskusikan kembali ,baik secara lisan maupun tulisan yang ketebalannya antara 10-25 halaman (Suryoputro, dkk. 2012:5; Nasucha dkk., 2009: 59). Artikel ilmiah memiliki beberapa ragam, yaitu artikel hasil penelitian, artikel non-penelitian (review paper/tinjauan pustaka), tinjauan buku (books review/resensi buku), obituari (obituary) / berita kematian ilmuan, laporan kasus, ceramah, dan editorial. Artikel yang akan dibahas dalam kegiatan pengabdian ini adalah artikel hasil penelitian.

Artikel hasil penelitian (research article) yaitu artikel yang diterbitkan dalam jurnal-jurnal ilmiah (Suryoputro, dkk. 2012). Artikel jenis ini berisi pelaksanaan dan hasil penelitian. Pemuatan artikel jenis ini bertujuan untuk membuka wacana diskusi dan kemungkinan penelitian baru, sekaligus untuk mengetahui apakah teori-teori atau pandanganpandangan yang terkait dengan masalah yang diteliti layak untuk untuk tetap diikuti atau harus ditinjau kembali. Nama lain dari artikel hasil penelitian adalah "artikel asli," biasanya merupakan artikel ilmiah hasil penelitian, atau dapat berupa konsep-konsep asli yang dikembangkan dari artikel-artikel ilmiah yang dipublikasikan. Artikel ilmiah hasil penelitian biasa memiliki sistematika mulai dari judul, penulis, instansi penulis, alamat email penulis, abstrak, pendahuluan, metode penelitian, hasil penelitian dan pembahasan, simpulan dan saran, ucapan terima kasih, dan daftar pustaka (Abdullah, 2014).

Artikel hasil penelitian ini juga disusun sebaiknya perlu melihat dulu gaya selingkung atau template jurnal nasional khususnya jurnal nasional terakreditasi yang akan dituju penulis. Jurnal nasional terakreditasi adalah jurnal ilmiah nasional yang diakreditasi oleh Kemristekdikti (Juknis Permenristekdikti, No. 20 Tahun 2017). Jurnal nasional terakreditasi juga merupakan terbitan berkala yang menyebarluaskan perkembangan ilmu pengetahuan, diterbitkan secara resmi dengan ISSN dan disebarluaskan melalui website secara open journal system yang sudah diakreditasi Dikti (Abdullah, 2014). Jurnal ini melibatkan pakar nasional sebagai mitra bestari, diminati pakar dari luar lingkungan sendiri, dan didistribusikan secara nasional dan diakreditasi oleh Dikti dengan level jurnal Sinta 1 s.d. Sinta 6.

Proses publikasi pada jurnal nasional terakreditasi juga sekarang melalui sistem Open Journal 
System (OJS). Para guru bahasa Indonesia dalam hal ini, juga perlu memahaminya dan mencoba mempraktikkannya secara langsung. Proses publikasinya, biasanya para penulis biasanya melakukan registrasi terlebih dahulu. Kemudian, melakukan submit artikel secara online dan menunggu hasil review dari pihak editor. Setelah itu, apabila artikel kita diterima biasanya kita akan diminta memperbaiki artikel sesuai saran reviewer. Apabila artikel sudah diangap baik dan benar sesuai permintaan editor, maka penulis akan menerima konfirmasi diterimanya (accpeted) artikel dan diminta untuk membayar biaya publikasi (Abdullah, 2014). Ada juga beberapa jurnal nasional terakreditasi yang dibebaskan dari biaya publikasi, tetapi hanya sedikit sekali jumlahnya. Hal ini menjadi kendala juga bagi guru karena biaya insentif bagi guru belum ada, berbeda dengan dosen.

Kemudian, hasil wawancara dengan Ketua MGMP Bahasa Indonesia tingkat SMA Kota Bengkulu, Ibu Dessy Yulistiani, M.Pd. bahwa dari 50 guru bahasa Indonesia yang aktif di MGMP rata-rata mendududuki jabatan fungsional dengan golongan III/d. Kesulitan mereka untuk naik pangkat adalah sulitnya untuk publikasi artikel ilmiah. Hal ini sesuai dengan Permen Menpan Nomor 16 Tahun 2009 dan Mendiknas Nomor 3/V/PB/2010 tentang aturan perhitungan angka kredit jabatan serta petunjuk pelaksanaan jabatan fungsional guru. Salah satu aturannya berbunyi "Untuk kenaikan jabatan/pangkat setingkat lebih tinggi dari Guru Pertama, pangkat Penata Muda, golongan ruang III/a sampai dengan Guru Utama, pangkat Pembina Utama, golongan ruang IV/e wajib melakukan kegiatan pengembangan keprofesian berkelanjutan pengembangan diri, publikasi dan/atau karya inovatif" (Menpan, 2009).

Permen Menpan Nomor 16 Tahun 2009 dan Mendiknas Nomor 3/V/PB/201 menjelaskan bahwa guru wajib mempunyai publikasi karya ilmiah jika ingin mengusulkan kenaikan pangkat mulai dari golongan III/A. Peraturan ini berlaku terhitung sejak tanggal 1 Januari 2013. Inilah yang menjadi permasalahan utama MGMP Bahasa Indonesia SMA saat ini. Sebagian besar dari mereka masih kesulitan untuk membuat karya ilmiah. Mereka juga masih minim informasi tentang bagaimana cara agar karya ilmiah yang dihasilkan dapat dipublikasikan. Berdasarkan masalah yang dipaparkan di atas, dibutuhkan suatu pelatihan khusus apalagi di masa pandemi Covid-19 yang dilarang pertemuan dalam bentuk tatap muka langsung. Untuk itu, dilakukan pelatihan dalam bentuk webinar yang dapat memfasilitasi guru-guru MGMP Bahasa Indonesia SMA Kota Bengkulu untuk meningkatkan keterampilan menulis artikel ilmiah dan juga bisa mempublikasikannya di jurnal nasional terakreditasi. Untuk itu, diharapkan pelatihan dalam bentuk webinar dapat dilaksanakan sesegera mungkin melalai telekonferensi Zoom Cloud Meeting dan media WhatsApp agar meningkatnya keterampilan para guru bahasa Indonesia di MGMP Bahasa Indonesia SMA Kota Bengkulu agar dapat menghasilkan artikel ilmiah yang terpublikasi di jurnal nasional terakreditasi.

Zoom Cloud Meeting merupakan suatu aplikasi yang dapat menunjang kebutuhan komunikasi di manapun dan kapanpun dengan banyak orang tanpa harus bertemu fisik secara langsung (Darmawan, 2014). Aplikasi ini berupa video conference, dengan mudahnya bisa diinstall pada perangkat: a) PC (Personal Computer) dengan webcame; b) Laptop dengan webcame; dan c) Smartphone Android. Zoom Cloud begitulah sebutannya, aplikasi ini sangat cocok sekali untuk melakukan Video Conference, dengan ringannya bandwidth yang digunakan, tidak ada iklan di aplikasi tersebut, serta tidak terlalu banyak memakan resource memory apabila dijalankan di Android atau PC. Untuk melakukan registrasi, cukup memasukkan email di halaman utama laman zoom.us, dan nanti akan mendapatkan surel notifikasi Aktifasi Account, dan selanjutnya ikuti langkahnya sesuai panduan yang diberikan.

Dari kelebihan Zoom Cloud Meeting yang bisa dilakukan secara daring dan tidak dibatasi waktu dan tempat diharapakan berhasilnya kegiatan Webinar dan Pendampingan Daring Penulisan Artikel Hasil Penelitian pada Jurnal Nasional Terakreditasi bagi Guru Bahasa Indonesia Tingkat SMA Kota Bengkulu.

\section{Bahan dan Metode}

Metode dalam melaksananakan Webinar dan Pendampingan Daring Penulisan Artikel Hasil Penelitian pada Jurnal Nasional Terakreditasi bagi Guru Bahasa Indonesia Tingkat SMA Kota Bengkulu yaitu menggunakan metode webinar dan pendampingan secara daring melalui aplikasi telekonferensi Zoom. Teknik pengabdian kepada masyarakat dengan teknik ceramah, diskusi, praktik, dan pemberian video tutorial sehingga memberikan pemahaman terkait proses menulis artikel ilmiah dan publikasi artikel ilmiah di jurnal nasional terakreditasi. Kemudian, dilanjutkan juga pendampingan menulis dan publikasi artikel ilmiah melalui Zoom dan dibantu dengan media groups WhatsApp dengan teknik diskusi, curah pendapat (brainstorming), dan praktik. Dengan pendampingan melalui Zoom dan groups WhatsApp maka diharapkan dapat memantau secara langsung perkembangan hasil kegiatan menulis artikel ilmiah dan proses publikasi artikel ilmiah para guru bahasa Indonesia di jurnal nasional terakreditasi.

Pelaksanaan webinar dan pendampingan ini Webinar dan Pendampingan Daring Penulisan Artikel Hasil Penelitian pada Jurnal Nasional Terakreditasi bagi 
Guru Bahasa Indonesia Tingkat SMA Kota Bengkulu yaitu dari tanggal tanggal 6 Oktober s.d. 3 November 2020. Pelaksaan diawali dengan kegiatan webinar pada tanggal 6 Oktober dan dilanjutkan dengan pendampingan dari tanggal 7 Oktober s.d. 3 November 2020.

Teknik pengumpulan data menggunakan teknik angket, dokumentasi, dan observasi sehingga instrumennya yaitu angket, record video Zoom, gawaim dan lembar observasi. Teknik angket untuk melihat respons peserta tentang sejauh mana pemahaman tentang menulis artikel ilmiah dan proses publikasi artikel ilmiah di jurnal nasional terakreditasi. Teknik dokumentasi dengan cara mendokumentasikan kegiatan webinar dan pendampingan dalam bentuk video webinar, foto kegiatan, dan arsip artikel ilmiah hasil penelitian yang sudah disusun, serta dokumen terkait bukti submit dan diterimanya artikel di jurnal nasional terakreditasi. Kegiatan observasi berupa lembar observasi keaktifan dan pemahaman peserta selama kegiatan webinar dan pendampingan secara daring.

Teknik analisis data dengan cara mereduksi data hasil angket, dokumentasi, dan lembar observasi. Dari hasil reduksi kemudian diinterpretasikan masing-masing sesuai dengan temuan sesuai rumusan masalah. Kemudian, disimpulkan hasil interpretasi dalam menjawab dua rumusan masalah pengabdian kepada masyarakat.

\section{Hasil dan Pembahasan}

\section{a. Hasil}

1. Hasil Pemahaman Guru Bahasa Indonesia SMA Kota Bengkulu dalam Menulis Artikel Ilmiah

Hasil angket respons dari 37 peserta setelah mengikuti webinar dan pendampingan daring penulisan artikel hasil penelitian pada jurnal nasional terakreditasi bagi guru bahasa Indonesia tingkat SMA Kota Bengkulu menunjukkan bahwa guru bahasa Indonesia sudah sudah mampu menulis artikel dengan cukup baik, mulai dari menulis judul, abstrak, pendahuluan, metode, hasil penelitian, pembahasan, simpulan dan saran, serta daftar pustaka. Akan tetapi, beberapa guru masih kesulitan dalam menuangan bagian pendahuluan terutama dalam memetakan posisi penelitian berdasarkan hasil penelitian relevan, kesulitaan dalam menuangkan pembahasan terutama menemukan kebaruan hasil penelitiannya, dan kesulitan mencari referensi dari jurnal online. Berikut hasil angket respons peserta terhadap pelaksanaan webinar dan pendampingan daring penulisan artikel hasil penelitian pada jurnal nasional terakreditasi bagi guru bahasa Indonesia tingkat SMA Kota Bengkulu yang dilaksanakan mulai dari 6 Oktober s.d. 3 November 2020.
Tabel 1. Hasil Angket Respons dari 37 Peserta setelah Mengikuti Webinar dan Pendampingan Daring

\begin{tabular}{|c|c|c|c|c|}
\hline \multirow[t]{2}{*}{ No } & \multirow[t]{2}{*}{ Item Pertanyaan } & \multicolumn{2}{|c|}{$\begin{array}{c}\text { Jumlah } \\
\text { Jawaban dari } \\
\text { Peserta }\end{array}$} & \multirow{2}{*}{$\begin{array}{c}\% \\
\text { Tingkat } \\
\text { Pemaham } \\
\text { an }\end{array}$} \\
\hline & & $\mathrm{Ya}$ & Tidak & \\
\hline A. & Kegiatan Menulis Artikel Ilmiah & & & \\
\hline 1. & $\begin{array}{l}\text { Apakah Anda mampu menuangkan } \\
\text { judul yang menarik? }\end{array}$ & 37 & - & $100 \%$ \\
\hline 2. & $\begin{array}{l}\text { Apakah Anda sudah mampu membuat } \\
\text { abstrak yang baik sesuai pola } \\
\text { IMRAD? }\end{array}$ & 30 & 7 & $81 \%$ \\
\hline 3. & $\begin{array}{l}\text { Apakah Anda sudah mampu membuat } \\
\text { pendahuluan yang mempunyai } \\
\text { kebaruan dan menjelaskan posisi } \\
\text { penelitian? }\end{array}$ & 20 & 17 & $54 \%$ \\
\hline 4. & $\begin{array}{l}\text { Apakah Anda sudah mampu } \\
\text { menuangkan metode penelitian? }\end{array}$ & 37 & - & $100 \%$ \\
\hline 5. & $\begin{array}{l}\text { Apakah Anda sudah mampu } \\
\text { menuangkan hasil penelitian berbasis } \\
\text { data kuantitatif dan/atau kualitatif? }\end{array}$ & 37 & - & $100 \%$ \\
\hline 7. & $\begin{array}{l}\text { Apakah Anda sudah mampu } \\
\text { menuangkan pembahasan yang } \\
\text { mengandung kebaruan dan memiliki } \\
\text { makna yang bermanfaat dalam } \\
\text { pengembangan penelitian } \\
\text { selanjutnya? }\end{array}$ & 15 & 22 & $40,5 \%$ \\
\hline 8. & $\begin{array}{l}\text { Apakah Anda sudah mampu } \\
\text { menuangkan kesimpulan dan saran } \\
\text { penelitian berdasarkan hasil penelitian } \\
\text { dan pembahasan? }\end{array}$ & 37 & - & $100 \%$ \\
\hline 9. & $\begin{array}{l}\text { Apakah Anda sudah mampu } \\
\text { menyusun daftar pustaka sesuai } \\
\text { format yang diminta pihak jurnal? }\end{array}$ & 28 & 9 & $75,7 \%$ \\
\hline 10. & $\begin{array}{l}\text { Apakah Anda sudah mampu menacari } \\
\text { referensi } 5 \text { tahun terakhir dari jurnal } \\
\text { online yang sesuai dengan topik } \\
\text { penelitian? }\end{array}$ & 18 & 19 & $48,6 \%$ \\
\hline
\end{tabular}

Narasumber dalam kegiatan webinar dan pendampingan daring penulisan artikel hasil penelitian pada jurnal nasional terakreditasi bagi guru bahasa Indonesia tingkat SMA Kota Bengkulu yaitu: 1) Dr. Rokhmat Basuki, M.Hum. (FKIP, Universitas Bengkulu); 2).Dr. Dian Eka Chandra Wardhana, M.Pd. (FKIP, Universitas Bengkulu); dan Dr. Noermanzah, M.Pd. (FKIP, Universitas Bengkulu).

Kegiatan pengabdian ini merupakan kerja sama Program Studi Magister Pendidikan Bahasa Indonesia dengan MGMP Bahasa Indonesia SMA Kota Bengkulu. Dalam sambutannya ibu Dessi Yulistiani, M.Pd. selaku Ketua MGMP Bahasa Indonesia SMA Kota Bengkulu mengucapkan terima kasih kepada Program Magister Pendidikan Bahasa Indonesia yang telah memfasilitasi kegiatan yang sangat dibutuhkan oleh para guru terutama dalam meningkatkan kemampuan menulis artikel ilmiah dan sebagai alternatif syarat kenaikan pangkat para guru. Kegiatan ini juga dibuka langsung oleh ibu Dr. Dian Eka Chandra Wardhana, M.Pd. selaku 
Koordinator Program Magister Pendidikan Bahasa Indonesia, FKIP Universitas Bengkulu. Ibu Koordinator berpesan agar kegiatan pengabdian ini bisa dilaksanakan dengan baik oleh para guru dan harapannya para guru dapat mempublikasikan hasil penelitiannya di sekolah pada jurnal nasional terakreditasi sebagai salah satu syarat untuk kenaikan pangkat.

Pada kesempatan pengabdian ini, para narasumber di hari pertama, yaitu 6 Oktober 2020 memberikan materi dan praktik langsung dalam menyusun artikel dan proses mengirimkan artikelnya pada jurnal nasional terakreditasi. Berikut materi yang disampaikan oleh ketiga narasumber dalam kegiatan pengabdian ini. 1) Dr. Rokhmat Basuki, M.Hum. menyampaikan materi tentang: a) Hakikat dan Sistematika Artikel Jurnal Ilmiah Nasional Terakreditasi; b) Perbedaan Jurnal Nasional, Jurnal Nasional Terakreditasi Sinta, Jurnal Internasional, dan Jurnal Internasional Bereputasi; c) Cara Pengutipan Artikel Jurnal Ilmiah; d) Menghindari Plagiarisme dalam Menulis Artikel Jurnal Ilmiah; dan e) Kiat Diterimanya Artikel Hasil Penelitian pada Jurnal Nasional Terakreditasi

2) Dr. Dian Eka Chandra Wardhana, M.Pd. menyampaikan materi tentang: a) Penulisan Judul Artikel Jurnal Ilmiah yang Menarik; b) Penulisan Pendahuluan Artikel Jurnal Ilmiah yang Mengandung Novelty; c) Penulisan Metode Penelitian Artikel Jurnal Ilmiah; d) Penulisan Hasil Penelitian dan Pembahasan Artikel Jurnal Ilmiah; dan e) Penulisan Simpulan dan Saran Artikel Jurnal Ilmiah. Kemudian, 3) Dr. Noermanzah, M.Pd. menyampaikan materi tentang: a) Publikasi Artikel Hasil Penelitian pada Jurnal Berbasis Open Journal Systems (OJS), b) Cara Menggunakan Program Plagiasi Ithenticate dan Plagiarism Checker, c) Penggunaan Sistem Citation dan Reference Manager dalam Membuat Daftar Pustaka menggunakan Mendeley; d) Praktik Pengiriman Artikel ke Jurnal Nasional Terakreditasi.

Kegiatan pengabdian berikutnya yaitu pada tanggal 7 Oktober s.d. 3 November 2020 dilanjutkan dengan Pendampingan secara daring menggunakan Zoom Cloud Meeting dan WhatsApp. Para peserta dalam kegiatan pendampingan juga sangat antusias ketika membuat artikel yang disesuaikan dengan aturan penulis jurnal yang akan dituju dan antusias dalam mengirimkan artikel ke jurnal nasional terakreditasi.

Kemudian, dari hasil analisis dokumentasi artikel ilmiah hasil penelitian yang disusun oleh guru bahasa Indonesia sebanyak 48,6\% guru yang sudah mengumpulkan artikel hasil penelitian dan $51,4 \%$ belum membuat artikel hasil penelitian. Selain itu, baru $10 \%$ yang diterima artikel hasil penelitiannya di jurnal nasional terakreditasi Sinta 4. Dari beberapa tingkat pemahaman guru bahasa Indonesia yang kurang ini, berdasarkan hasil observasi bahwa para guru masih belum terbiasa bekerja melalui sistem webinar dan pendampingan secara daring sehingga banyak guru yang masih kesulitan dalam menulis artikel ilmiah. Para guru juga dari hasil observasi mengeluhkan pada waktu tanya jawab yang dibatasi oleh waktu ketika webinar melalui Zoom.

2. Hasil Pemahaman Guru Bahasa Indonesia SMA Kota Bengkulu dalam Proses Publikasi Artikel Ilmiah di Jurnal Nasional Terakreditasi

Pemahaman guru bahasa Indonesia dalam melakukan proses publikasi sudah mencapai $67,6 \%$ bisa melakukan register dan $59,4 \%$ bisa sumbit ke jurnal nasional terakreditasi. Berikut salah satu foto peserta yang sedang melakukan registrasi dan sumbit di jurnal Silampari Bisa: Jurnal Penelitian Pendidikan Bahasa Indonesia, Daerah, dan Asing.

Kemudian, dari hasil analisis dokumentasi dan observasi artikel yang sudah disubmit sudah $10 \%$ yang diterima artikelnya di jurnal nasional terakreditasi pada tanggal 31 November 2020. 10\% artikel ini sudah diterima di beberapa jurnal terakreditasi Sinta 4, seperti jurnal Diglosia : Jurnal Pendidikan, Kebahasaan, dan Kesusastraan Indonesia dan Silampari Bisa: Jurnal Penelitian Pendidikan Bahasa Indonesia, Daerah, dan Asing. Berikut hasil dari angket respons peserta setelah mengikuti proses webinar dan pendampingan publikasi di jurnal nasional terakreditasi.

Tabel 2. Hasil Angket Respons dari 37 Peserta setelah Mengikuti Proses Webinar dan Pendampingan Publikasi di Jurnal Nasional Terakreditasi

\begin{tabular}{|c|l|c|c|c|}
\hline \multirow{2}{*}{ No. } & \multicolumn{3}{|c|}{ Item Pertanyaan } & \multicolumn{2}{|c|}{$\begin{array}{c}\text { Jumlah } \\
\text { Jawaban dari } \\
\text { Peserta }\end{array}$} & \multirow{2}{*}{$\begin{array}{c}\text { \% Tingkat } \\
\text { Pemahaman }\end{array}$} \\
\cline { 1 - 3 } B. & \multicolumn{2}{|c|}{$\begin{array}{l}\text { Proses Publikasi di Jurnal Nasional Terakreditasi Berbasis } \\
\text { Open Journal Systems (OJS) }\end{array}$} \\
\hline 1. & $\begin{array}{l}\text { Apakah Anda sudah mampu } \\
\text { register atau mendaftar di } \\
\text { jurnal nasional terakreditasi } \\
\text { berbasis Open Journal Systems } \\
\text { (OJS)? }\end{array}$ & 28 & 12 & \multirow{2}{*}{$67,6 \%$} \\
\hline 2. & $\begin{array}{l}\text { Apakah Anda sudah mampu } \\
\text { melakukan proses submit atau } \\
\text { mengirim artikel ilmiah ke } \\
\text { jurnal nasional terakreditasi } \\
\text { berbasis Open Journal Systems } \\
\text { (OJS)? }\end{array}$ & 22 & 15 & \\
\hline 3. & $\begin{array}{l}\text { Apakah Anda sudah mampu } \\
\text { melakukan kegiatan } \\
\text { memperbaiki hasil review di } \\
\text { jurnal nasional terakreditasi } \\
\text { berbasis Open Journal Systems } \\
\text { (OJS)? }\end{array}$ & 8 & 29 & $21,6 \%$ \\
\hline
\end{tabular}




\section{b. Pembahasan}

Webinar dan pendampingan daring penulisan artikel hasil penelitian pada jurnal nasional terakreditasi bagi guru bahasa Indonesia tingkat SMA Kota Bengkulu yang dilaksanakan mulai dari 6 Oktober s.d. 3 November 2020 melalui Zoom Cloud dan Whatsapp cukup memberikan dampak yang positif kepada para guru bahasa Indonesia terhadap pemahaman menulis artikel ilmiah dan proses mempublikasikannya di jurnal nasional terkareditasi. Bahkan, para peserta sudah ada yang mampu memperoleh surat penerimaan dari jurnal nasional terakreditasi Sinta 4 yaitu sekitar $10 \%$. Walaupun yang kita ketahui, menulis artikel ilmiah dan proses publikasi membutuhkan waktu yang cukup lama. Hal ini dialami oleh Putra dan Syaputra (2019:214) dalam pengabdian kepada masyarakatnya dengan judul Workshop Publikasi Artikel Ilmiah dalam Jurnal Nasional Guru SMP Pangkalpinang yang menunjukkan bahwa hasil pengabdiannya baru sebatas peserta mampu registrasi di jurnal nasional terakreditasi dan para peserta belum ada yang mampu submit atau mengirimkan artikelnya ke jurnal nasional terkareditasi.

Begitupun pengabdian yang sudah dilakukan oleh Susetyo (2020:28) dengan judul Peningkatan Profesionalisme Guru Bahasa Indonesia di Kabupaten Musirawas Sumatera Selatan Melalui Pelatihan Menulis Artikel Jurnal Ilmiah baru sebatas pesertanya mampu menulis artikel ilmiah dengan gaya selingkung jurnal nasional dan mampu melakukaka registrasi. Belum sampai pada tahap submit dan diterima artikelnya di jurnal nasional terakreditasi Sinta seperti pada webinar dan pendampingan daring penulisan artikel hasil penelitian pada jurnal nasional terakreditasi bagi guru bahasa Indonesia tingkat SMA Kota Bengkulu yang sudah dilaksanakan dari 6 Oktober s.d. 3 November 2020.

Pemahaman yang cukup baik dari peserta webinar dan pendampingan yaitu mereka sudah mampu menulis artikel dengan cukup baik, mulai dari menulis judul, abstrak, pendahuluan, metode, hasil penelitian, pembahasan, simpulan dan saran, serta daftar pustaka. Akan tetapi, beberapa guru masih kesulitan dalam menuangan bagian pendahuluan terutama dalam memetakan posisi penelitian berdasarkan hasil penelitian relevan, kesulitaan dalam menuangkan pembahasan terutama menemukan kebaruan hasil penelitiannya, dan kesulitan mencari referensi dari jurnal online. Hal ini juga masih relevan dengan pengabdian yang dilakukan oleh Yanti dkk. (2018:87-88) bahwa kesulitan para guru bahasa Indonesia tingkat SMA di Kota Bengkulu dalam menulis artikel ilmiah yaitu disebabkan oleh faktor kemampuan, psikologis, ekonomi. Dalam hal ini yang masih dominan dialami para guru bahasa Indonesia yaitu kemampuan dalam menuangkan artikel khususnya pada bagian pendahuluan dan pembahasan.
Selain itu, faktor ekonomi menjadi faktor utama juga karena publikasi di jurnal nasional terakreditasi membutuhkan biaya yang cukup tinggi. Walaupun peruntukan anggaran bagi guru yang sudah tersertifikasi adalah salah satunya pengembangan profesionalisme dalam menulis artikel ilmiah dan publikasi di jurnal nasional terakreditasi masih dirasa belum cukup. Apalagi bagi para guru belum ada bantuan khusus atau insentif bagi yang bisa publikasi di jurnal nasional terakreditasi dan jurnal internasional, baik dari sekolah, dinas pendidikan, maupun kementerian. Seharusnya guru harus lebih bijak dan berpikir panjang apabila sudah memiliki artikel yang dipublikasi di jurnal nasional terakreditasi persyaratan kenaikan jabatan dari III/c ke atas sudah terpenuhi (Permenpan dan RB Nomor 16 Tahun 2009) sehingga akan menaikkan tunjangan.

Kemudian, dari hasil analisis dokumentasi artikel ilmiah hasil penelitian yang disusun oleh guru bahasa Indonesia SMA di Kota Bengkulu sebanyak 48,6\% guru yang sudah mengumpulkan artikel hasil penelitian dan $51,4 \%$ belum membuat artikel hasil penelitian. Selain itu, baru $10 \%$ yang diterima artikel hasil penelitiannya di jurnal nasional terakreditasi Sinta 4. Dari beberapa tingkat pemahaman guru bahasa Indonesia yang kurang ini, berdasarkan hasil observasi bahwa para guru masih belum terbiasa bekerja melalui sistem webinar dan pendampingan secara daring sehingga banyak guru yang masih kesulitan dalam menulis artikel ilmiah. Para guru juga dari hasil observasi mengeluhkan pada waktu tanya jawab yang dibatasi oleh waktu ketika webinar melalui Zoom. Sistem pelatihan bahkan pembelajaran daring memang tidak semaksimal dilakukan secara luring atau tatap muka. Walaupun ada beberapa hasil penelitian bahwa pembelajaran daring cukup membantu dalam meningkatkan pemahaman pesertanya. Seperti penelitian yang dilakukan oleh Khusniyah dan Hakim (2019:19) bahwa pembelajaran daring berbantuan web blog berpengaruh positif terhadap peningkatan khususnya kemampuan membaca bahasa Inggris peserta didik. Hal ini menunjukkan bahwa hasil ini bisa saja berbeda karena webinar dan pendampingan yang dilakukan pesertanya lahir pada generasi yang belum mengenal teknologi informasi daring. Untuk itu, memang sebelum memberikan pelatihan kepada para guru bahasa Indonesia tingkat SMA di Kota Bengkulu perlu persiapan khusus dan dibekali terlebih dahulu bagaimana mengoperasikan Zoom dan WhatsApp serta diperpanjang waktunya dalam pemberian pemahaman dalam proses publikasi di jurnal nasional terakreditasi yang sudah berbasis Open Journal Systems (OJS).

Dari hasil webinar dan pendampingan ini juga sudah menunjukkan hasil yang cukup baik, yang mana pemahaman guru bahasa Indonesia dalam melakukan proses publikasi artikel ilmiah, 67,6\% bisa melakukan 
register dan $59,4 \%$ bisa sumbit ke jurnal nasional terakreditasi. Kemudian, dari hasil analisis dokumentasi dan observasi artikel yang sudah disubmit sudah $10 \%$ yang diterima artikelnya di jurnal nasional terakreditasi pada tanggal 31 November 2020. 10\% artikel ini sudah diterima di beberapa jurnal terakreditasi Sinta 4, seperti jurnal Diglosia : Jurnal Pendidikan, Kebahasaan, dan Kesusastraan Indonesia dan Silampari Bisa: Jurnal Penelitian Pendidikan Bahasa Indonesia, Daerah, dan Asing. Berikut hasil dari angket respons peserta setelah mengikuti proses webinar dan pendampingan publikasi di jurnal nasional terakreditasi. Hal ini menunjukkan bahwa para guru bahasa Indonesia tingkat SMA di Kota Bengkulu sudah mulai menyesuaikan kegiatan webinar dan pendampingan secara daring.

\section{Simpulan}

Pelaksanan pengabdian kepada masyarakat penerapan IPTEKS ini menghasilkan beberapa hal sebagai berikut:

a. Pemahaman guru bahasa Indonesia tingkat sekolah menengah atas Kota Bengkulu dalam menulis artikel ilmiah melalui kegiatan webinar dan pendampingan secara daring sudah mampu menulis artikel dengan baik, mulai dari menulis judul, abstrak, pendahuluan, metode, hasil penelitian, pembahasan, simpulan dan saran, serta daftar pustaka. Akan tetapi, beberapa guru masih kesulitan dalam menuangan bagian pendahuluan dalam memetakan posisi penelitian berdasarkan hasil penelitian relevan, masih sulit menuangkan pembahasan terutama menemukan kebaruan hasil penelitiannya, dan masih sulit mencari referensi dari jurnal online.

b. Pemahaman guru bahasa Indonesia tingkat sekolah menengah atas Kota Bengkulu dalam proses publikasi artikel ilmiah di jurnal nasional terakreditasi melalui kegiatan webinar dan pendampingan secara daring sudah mencapai $67,6 \%$ bisa melakukan register dan $59,4 \%$ bisa sumbit ke jurnal nasional terakreditasi. Kemudian, sudah $10 \%$ yang diterima artikelnya di jurnal nasional terakreditasi dan $48,6 \%$ hanya pada tahap menulis artikel hasil penelitian dan $51,4 \%$ belum membuat artikel hasil penelitian.

\section{Ucapan Terima Kasih}

Tim pengabdian kepada masyarakat mengucapkan terima kasih terutama kepada FKIP Universitas Bengkulu yang sudah membantu memberikan dana kegiatan pengabdian ini. Ucapan terima kasih juga kami sampaikan kepada Ketua MGMP Bahasa Indonesia SMA Kota Bengkulu dan jajarannya yang sudah berkenan membantu mengoordinasikan dan mengondisikan peserta untuk bisa hadir secara virtual dalam pengabdian kepada masyarakat ini.

\section{Daftar Pustaka}

Abdullah, M. (2014). Menembus Jurnal Ilmiah Nasional \& Internasional. Jakarta: Gramedia Pustaka Utama.

Blumner, J. (2008). Beyond the Reactive: WAC Programs and the Steps Ahead dalam Joumal on Writing Across the Curriculum. Michigan, USA: University of Michigan.

Darmawan, D. (2014). Pengembangan E-Learning Teori dan Desain. Bandung: PT Remaja Rosdakarya.

Firmansyah, B. M. dan Syafrina, D. (2018). Karakteristik Guru Mata Pelajaran Bahasa Indonesia yang Profesional. https://www.researchgate.net/publication/323823 038_KARAKTERISTIK_GURU_MATA_PELA JARAN_BAHASA_INDONESIA_YANG_PRO FESIONAL

Juknis Permenristekdikti No 20 Tahun 2017 tentang Jurnal Nasional Terakreditasi.

Kellog, R. (2008). Training Writing Skills: A Cognitive Developmental Perspective Journal of Writing Research. USA: Department of Psychology, Saint Louis University.

Khusniyah, N. L. \& Hakim, L. (2019). Efektivitas Pembelajaran Berbasis Daring: Sebuah Bukti pada Pembelajaran Bahasa Inggris. Jurnal Tatsqif, 17(1), $19 . \quad$ Available at: http://dx.doi.org/10.20414/jtq.v17i1.667.

Mendiknas Nomor 3/V/PB/2010 tentang Aturan Perhitungan Angka Kredit Jabatan.

Musaffak dan Pangesti, F. (2018). Penerapan Strategi Mind Mapping sebagai Upaya Peningkatan Kemampuan Mahasiswa dalam Menulis Artikel Ilmiah. Belajar Bahasa, 3(2). doi:10.32528/bb.v3i2.1589

Nasucha, Y., Rohmadi, M., Wahyudi, A., \& Kusumawati, Y. (2009). Bahasa Indonesia untuk Penulisan Karya Tulis Ilmiah: Mata Kuliah Wajib Pengembangan Kepribadian. Yogyakarta: Media Perkasa.

Peraturan Pemerintah (PP) Nomor 19 Tahun 2005 tentang Standar Nasional Pendidikan.

Permenpan dan RB Nomor 16 Tahun 2009 tentang Jabatan Fungsional Guru dan Angka Kreditnya.

Putra, Y. Y. \& Saputra, A. (2019). Workshop Publikasi Artikel Ilmiah dalam Jurnal Nasional Guru SMP Pangkalpinang. JPMB : Jurnal Pemberdayaan Masyarakat Berkarakter, 2(2), 214. doi:10.36765/jpmb.v2i2.16

Suryoputro, G., dkk. (2012). Menulis Artikel untuk Jurnal Ilmiah. Jakarta Selatan: Uhamka Press. 
Susetyo, S., Basuki, R., \& Noermanzah, N. (2020). Peningkatan Profesionalisme Guru Bahasa Indonesia di Kabupaten Musirawas Sumatera Selatan Melalui Pelatihan Menulis Artikel Jurnal Ilmiah. ABDI: Jurnal Pengabdian dan Pemberdayaan Masyarakat, 2(1), 28. doi:10.24036/abdi.v2i1.35
Undang-Undang Nomor 14 Tahun 2005 tentang Guru dan Dosen.

Yanti, N., Hiasa, F., \& Arono, A. (2018). Pelatihan Penulisan Karya Ilmiah Pada Musyawarah Guru Mata Pelajaran (MGMP) Bahasa Indonesia di SMA/SMK Kota Bengkulu. Dharma Raflesia: Jurnal Ilmiah Pengembangan dan Penerapan IPTEKS, 16(1). doi:10.33369/dr.v16i1.4829 